\title{
Prevalence of abnormal glucose metabolism among adults attending an outpatient department at a tertiary referral hospital in Swaziland: a cross-sectional study
}

Mojeed Akorede Gbadamosi and Boikhutso Tlou

\begin{abstract}
Background: The exact prevalence of type 2 diabetes mellitus (T2DM) and pre-diabetes in Swaziland remains unknown. Estimates suggest that the prevalence rate of type 2 diabetes mellitus is between 2.5 and $6.0 \%$ in Swaziland. The disparity in these estimates is due to a lack of quality data but the prevalence of diabetes is increasing in Swaziland. This study estimates the prevalence of type 2 diabetes mellitus and pre-diabetes among patients in a tertiary hospital in Manzini, Swaziland.
\end{abstract}

Methods: A cross-sectional observational survey was used to estimate the crude and age-adjusted prevalence rates of diabetes and pre-diabetes (impaired fasting glucose (IFG) and impaired glucose tolerance (IGT)) in the Manzini regional referral hospital of Swaziland. Diabetes was defined as a fasting blood glucose (FBG) $\geq 7.0 \mathrm{mmol} / \mathrm{L}(126$ $\mathrm{mg} / \mathrm{dL})$ and pre-diabetes was defined as an FBG of $6.1-6.9 \mathrm{mmol} / \mathrm{L}(110-125 \mathrm{mg} / \mathrm{dL})$ and an FBG $<7.0 \mathrm{mmol} / \mathrm{L}(<$ $126 \mathrm{mg} / \mathrm{dL}$ ), respectively for IFG and IGT. A random sample of 385 participants was used. Data analysis was done using SPSS version 26 and the level of statistical significance was set at $a<0.05$.

Results: The crude prevalence of type 2 diabetes mellitus and pre-diabetes was $7.3 \%$ [95\% Cl 4.9-10.3] and 6.5\% [95\% Cl 4.2-9.4], respectively, with clear gender differences in the prevalence of diabetes (men 1.6\% vs women $5.7 \%, p=0.001)$. On the other hand, significantly more men (3.6\%) had pre-diabetes than women $(2.9 \%)(p=0.004)$. The overall age-adjusted prevalence rates of type 2 diabetes mellitus and pre-diabetes were 3.9 and 3.8\%, respectively. Among the diabetic group, 3 (10.7\%) had known T2DM, whereas 25 (89.3\%) were newly diagnosed during the study. Advancing age, gender, raised blood pressure, abnormal body mass index, and wealth index were significant risk factors for T2DM or prediabetes.

Conclusion: The prevalence of type 2 diabetes mellitus among adult outpatients in the Raleigh Fitkin Memorial hospital was higher than previously reported in the health facility in Manzini; suggesting the need for routine T2DM screening at outpatient departments.

Keywords: Abnormal glucose metabolism, Diabetes, Pre-diabetes, Prevalence, Swaziland

* Correspondence: 217081323@stu.ukzn.ac.za; gbmojeed@yahoo.com Discipline of Public Health Medicine, School of Nursing and Public Health, University of KwaZulu-Natal, Durban, South Africa

(c) The Author(s). 2020 Open Access This article is licensed under a Creative Commons Attribution 4.0 International License, which permits use, sharing, adaptation, distribution and reproduction in any medium or format, as long as you give appropriate credit to the original author(s) and the source, provide a link to the Creative Commons licence, and indicate if changes were made. The images or other third party material in this article are included in the article's Creative Commons licence, unless indicated otherwise in a credit line to the material. If material is not included in the article's Creative Commons licence and your intended use is not permitted by statutory regulation or exceeds the permitted use, you will need to obtain permission directly from the copyright holder. To view a copy of this licence, visit http://creativecommons.org/licenses/by/4.0/ The Creative Commons Public Domain Dedication waiver (http://creativecommons.org/publicdomain/zero/1.0/) applies to the data made available in this article, unless otherwise stated in a credit line to the data. 


\section{Background}

The exact prevalence of type 2 diabetes mellitus (T2DM) in Swaziland remains unknown. The International Diabetes Federation (IDF) [1] reported that the proportion of adults living with T2DM in Swaziland was $2.5 \%$. On the contrary, the World Health Organisation (WHO) [2] estimated the prevalence of T2DM in Swaziland to be $6 \%$. Both the IDF and WHO extrapolated data from a similar country to estimate the T2DM prevalence for Swaziland, due to absence of original data from Swaziland. Furthermore, a recent Stepwise approach to surveillance (STEPS) survey conducted in 2014 highlighted the significance of the burden of chronic diseases of lifestyle in Swaziland [3]. The survey findings revealed that about $14.2 \%$ of the respondents had raised blood glucose, while $9.8 \%$ had impaired fasting glycemia (IFG).

The STEPS survey [3] attributed the rising prevalence of chronic diseases (including diabetes mellitus) to the high rates of obesity, physical inactivity, smoking, and alcohol consumption in the Swazi population. Therefore, the Swaziland government established the National Non-Communicable Diseases Programme with a focus on cardiovascular diseases, diabetes, cancer, and other chronic diseases [4]. Furthermore, the Ministry of Health $(\mathrm{MOH})$ developed the National Non-Communicable Diseases Policy [5] and a strategic plan for 2012-2017 [6] to guide the implementation of non-communicable diseases (NCD) prevention, management, and control. There is thus a serious need for current epidemiological data.

Furthermore, about $8.8 \%$ of the STEPS respondents aged 40-69 years had cardiovascular disease [3]. The morbidity and mortality statistics for chronic diseases showed alarming rates [3]. The Swaziland Ministry of Health $(\mathrm{MOH})$ [4] also reported that diabetes mellitus was responsible for 73,290 attendances at out-patient departments of all health facilities in 2016, representing a $16.8 \%$ increase from the 2015 figures. Similarly, mortality due to diabetes mellitus was unacceptably high and has increased sharply from 45 cases in 2014, to 88 in 2015, and finally to 109 cases in 2016 [4].

To the researchers' knowledge, no epidemiological study has been conducted in Swaziland to estimate the age-adjusted prevalence of T2DM and pre-diabetes, even though diabetes ranked third among the ten leading causes of all hospital admissions in Swaziland in 2016 [4]. Previous studies in Swaziland have investigated the influence of diabetes on the quality of life [7] as well as the prevalence of diabetic retinopathy [8], and a case has been made for strengthening chronic care services in the kingdom [9]. Similarly, risk factors for noncommunicable diseases (NCDs) in Swaziland have been reported [3]. A study by Rabkin et al. in 2016 investigated the possibility of screening for diabetes among HIV-positive patients [10]. However, the study did not report age-adjusted prevalence rates for prediabetes and diabetes. To address these gaps, the current study was conducted to determine the prevalence of T2DM and pre-diabetes in a tertiary hospital in the Manzini region of Swaziland. Quantifying the prevalence of T2DM and pre-diabetes among patients attending the out-patient departments (OPD) at Raleigh Fitkin Memorial (RFM) will contribute to the understanding of the burden of T2DM in Swaziland. Findings from this study will facilitate planning and implementation of cost-effective interventions for the prevention and management of diabetes mellitus, by adding new scientific information to the existing body of knowledge.

\section{Methods \\ Study design}

This study was an observational, cross-sectional, hospital-based study.

\section{Study setting}

Raleigh Fitkin Memorial (RFM) Hospital, situated in the Manzini region, is the second largest public health facility in Swaziland. It is a regional referral and government sub-vented teaching hospital. The mission hospital and its different service units draw patients from the Manzini region as well as neighbouring communities in the adjacent regions including the Mbabane - Manzini - Siteki corridor.

\section{Population and sample}

A cross-sectional study was conducted from February to March 2019 among 385 patients who visited the OPD of the RFM Hospital in Manzini, Swaziland. All patients who visited the OPD during the data collection period were included. Patients were included in the sample if they resided in the Manzini region; were 18 years of age and above; had fasted for $8 \mathrm{~h}$ before the screening, and willingly consented to participate in the study. However, patients with active infection or using corticosteroids; who were pregnant; who had a temperature greater than $101.4^{\circ} \mathrm{F}\left(38.6^{\circ} \mathrm{C}\right)$; were taking antibiotics or anti-malaria medications or who were unwilling to participate were excluded. A representative sample of the medical and surgical outpatient population was surveyed. A systematic random sampling technique was applied to sample 385 individuals, whereby every 3 rd individual visiting the OPD was approached to participate in the study, bearing in mind the inclusion criteria. As remarked by Castillo [11], systematic random sampling allows the researchers to add a degree of a system into the random selection of subjects and ensures that the population is evenly sampled. 
The sample size was estimated with the formula for a cross-sectional study by Daniel [12]:

$$
\mathrm{n}=\frac{\mathrm{Z}^{2}(\mathrm{PQ})}{\delta^{2}}
$$

$\mathrm{Z}=1.96$. (The standard normal deviation at $95 \%$ confidence)

$P=0.5$ (Estimated prevalence of the problem under study, assumed to be $50 \%$ to achieve the maximum sample size)

$\mathrm{Q}=0.5((100 \%-\mathrm{P})($ or $1-\mathrm{P}))$

$\delta=0.05$ (The precision or maximum acceptable error)

$\mathrm{n}=$ Sample size

$\mathrm{n}=\frac{(1.96)^{2} \times(0.5)(0.5)}{(0.05)^{2}}$

$\mathrm{n}=384.16$

The sample size was 385 patients reporting to the Medical and Surgical out-patient departments of the Raleigh Fitkin Memorial Hospital. This method of sampling has some selection bias but it is easier to perform and less time consuming.

\section{Definitions}

The prevalence of T2DM was defined to comprise of all participants with known diabetes and those with a fasting blood glucose $(\mathrm{FBG}) \geq 7.0 \mathrm{mmol} / \mathrm{L}(126 \mathrm{mg} / \mathrm{dL})$ or a random blood glucose $(\mathrm{RBG}) \geq 11.1 \mathrm{mmol} / \mathrm{dL}(>200 \mathrm{mg} /$ $\mathrm{dL})$ and/or an oral glucose tolerance test (OGTT) $\geq 11.1$ $\mathrm{mmol} / \mathrm{dL}$ (> $200 \mathrm{mg} / \mathrm{dL}$ ). Prediabetes was defined as a FBG between 6.1 and $6.9 \mathrm{mmol} / \mathrm{L}(110-125 \mathrm{mg} / \mathrm{dL})$ for impaired fasting glucose (IFG) or an OGTT between 7.8 and $11.0 \mathrm{mmol} / \mathrm{L}(140-199 \mathrm{mg} / \mathrm{dL})$ for impaired glucose tolerance (IGT) based on the WHO/IDF recommendation [13]. Abnormal glucose metabolism (AGM) was defined as IFG, IGT, or T2DM.

\section{Measures \\ Demographics}

Demographic variables collected included age; gender; marital status; and residential location.

\section{Socio-economic status}

Participants were asked to report their level of education, categorised into five groups: no formal education; primary school; secondary school; high school; and tertiary education. Respondents' occupations and average monthly household incomes were also determined. Household wealth (assets, ownership of agricultural land and farm animals) was also recorded and used to generate wealth quintiles through principal component analysis (PCA). Principal component analysis was used to extract a set of uncorrelated principal components as weighted linear combinations of the original household asset ownership variables. Each principal component was the sum of each variable multiplied by its weight. The components were ordered so that the first principal component explained the largest amount of variation in the data. Therefore, the first principal component was used to represent the wealth index because it explained the largest possible amount of variation in the original data [14]. This wealth index was then ranked into five quintiles (since the wealth index was a continuous variable), dividing all participants into five equal groups; lowest, second, third, fourth, and the highest quintiles.

\section{Anthropometric variables}

Weight was measured in kilograms $(\mathrm{kg})$ using a weighing scale (FORA Digital Multi-function Diamond Scale), and height was measured in centimeters $(\mathrm{cm})$ using a stadiometer. Weight was measured with the participants wearing light clothing and barefoot. Waist and hip circumferences were assessed in centimeters $(\mathrm{cm})$ using a measuring tape. Waist and hip circumferences were assessed while the participants were in a standing position.

The Body mass index (BMI) was calculated as weight divided by height squared $\left(\mathrm{kg} / \mathrm{m}^{2}\right)$. Participants were classified as underweight if their BMI was $<18.5 \mathrm{~kg} / \mathrm{m}^{2}$, normal weight if their BMI was between 18.5 and 24.9 $\mathrm{kg} / \mathrm{m}^{2}$ (inclusive), overweight if their BMI was between 25.0 and $29.9 \mathrm{~kg} / \mathrm{m}^{2}$ (inclusive) and obese if their BMI was $\geq 30 \mathrm{~kg} / \mathrm{m}^{2}[15]$.

A raised waist circumference was defined as a waist circumference greater than $94 \mathrm{~cm}(>94 \mathrm{~cm})$ for men, and greater than $80 \mathrm{~cm}(>80 \mathrm{~cm})$ for women, while a raised waist-to-hip ratio (WHR) was defined as a WHR greater than one $(>1.0)$ for men and greater than zero point eight five $(>0.85)$ for women, according to standardised international criteria [16].

\section{Blood pressure}

Blood pressure was measured using a sphygmomanometer (FORA Fully Auto Desk P30 Plus Spygmo Digital with $24-43 \mathrm{~cm}$ WIDR Cuff). The blood Pressure measurement was taken while the participant was in the sitting position, using the right upper arm after a 5-min rest period. Two readings were taken during the interview at 15 min intervals.

Participants were hypertensive (stage 1) if their mean systolic blood pressure (SBP) was $130-139 \mathrm{mmHg}$ or their mean diastolic blood pressure (DBP) was 80-89 $\mathrm{mmHg}$. Stage 2 hypertension was defined as a mean SBP of $140-179 \mathrm{mmHg}$ and a DBP greater than or equal to $90 \mathrm{mmHg}$. Participants were considered to have hypertensive crisis if their mean SBP was greater than or equal to $180 \mathrm{mmHg}$ or if their mean DBP was greater than or equal to $120 \mathrm{mmHg}$. A mean SBP of $120-129$ and a mean DBP of less than $80 \mathrm{mmHg}$ was considered as an 
elevated blood pressure. Participants on antihypertensive treatment were also included. Hypertension definitions were made according to the American College of Cardiology/American Heart Association guidelines [17].

\section{Blood glucose}

The fasting blood glucose (FBG) and Oral Glucose Tolerance (OGT) testing were done using a glucometer (On Call $^{\circ}$ EZ II, ACON Laboratory, Inc., USA) according to the manufacturer's instructions. Fasting blood glucose was measured between 08:00 and 12:00, after a minimum of $8 \mathrm{~h}$ of overnight fasting. To determine the Oral Glucose Tolerance (OGT), $75 \mathrm{~g}$ of glucose (Dextrose Monohydrate, MEDICOLAB, South Africa) was dissolved in $300 \mathrm{ml}$ of water and given to the respondent to drink within 5 min after a taking an FBG reading. After a two- hour interval, the glucose test was performed again.

\section{Prevalence of pre-diabetes and type 2 diabetes mellitus}

The calculation of the prevalence of T2DM and prediabetes was based on the method used by Miller [18]. The number of cases of T2DM or pre-diabetes was divided by the sample size to obtain the crude prevalence of T2DM or pre-diabetes, respectively. The age-adjusted prevalence rates were calculated by dividing the number of cases of T2DM or pre-diabetes, respectively in each of the 10-year age groups by the number of cases in that group, before the result was multiplied by the population proportion for that age group, based on the Swaziland Demographic and Health Survey (DHS) report [19]. (See Supplementary file 1).

\section{Statistical analysis}

All analyses were conducted using SPSS version 26 statistical software (IBM Corp., Armonk, NY, USA). Descriptive statistics (percentage) was used to describe the crude (unadjusted) prevalence rates for the sample and age-adjusted prevalence rates of T2DM and prediabetes. A Chi-square test was applied to examine the association between the independent demographic and biometric variables and abnormal glucose metabolism (AGM) (T2DM and pre-diabetes). Analysis of variance (ANOVA) was used to examine the group and the main effect of the categorical independent variables (age groups, gender) on the continuous dependent fasting blood glucose (FBG). A two-sided $p$-value $<0.05$ was considered statistically significant.

\section{Results}

Description of the study population

Four hundred and eleven (411) subjects were interviewed among the 440 subjects invited to participate, yielding a response rate of $93.4 \%$. Of the 440 subjects invited, a total of 55 subjects were excluded due to being younger than 18 years of age (13 subjects), being resident outside of Manzini region (27 subjects), pregnancy (2 subjects), and high temperature (3 subjects). An individual withdrew for fear of the needle prick. Completed fasting blood glucose readings were available for 394 subjects but 9 subjects had completed questionnaires with missing data.

Table 1 shows the characteristics of the study participants. There were 197 (51.2\%) men and 188 (48.8\%) women. A typical participant in this study was 38 years of age, with women being older than men (39 vs 36 years). The participants were evenly distributed in terms of areas of residence, with $50.1 \%(n=192)$ and $49.9 \%$ $(n=191)$ from the rural and urban areas, respectively. A significantly higher proportion of women compared to men were overweight (33.5\% vs $19.8 \%)$ and obese $(33.5 \%$ vs $6.6 \%$ ), unemployed (32.4\% vs $21.8 \%$ ), and from poor households (35.1\% vs $20.8 \%$ ). More men were significantly underweight (9.6\%) than women (1.1\%). Also, more men attained high school or college education than women (48.7\% vs $34.0 \%)$. The mean systolic and diastolic blood pressures were 123.13 (16.22) $\mathrm{mmHg}$ and 77.83 (11.33) $\mathrm{mmHg}$, respectively. According to the American College of Cardiology/American Heart Association's (ACC/AHA) definition of hypertension [17], $36.9 \%$ of the study participants had normal blood pressure, $14.8 \%$ of them had pre-hypertension and 29.4 and $17.4 \%$ had stage 1 and 2 hypertensions, respectively, while six participants (1.6\%) had hypertensive crisis. There was no significant gender difference in the prevalence of hypertension.

\section{Prevalence of pre-diabetes and type 2 diabetes mellitus}

The overall prevalence rates of T2DM and prediabetes were 7.3 and $6.5 \%$, respectively. The prevalence of T2DM was higher in women (3.6\%) than men $(2.9 \%)$. On the contrary, the prevalence of prediabetes was higher in men $(5.7 \%)$ compared to women (1.6\%). Based on the Swaziland national population estimates [19], the age-adjusted prevalence rates for T2DM and pre-diabetes were $3.9 \%$ ( $1.2 \%$ men vs $6.6 \%$ women) and $3.8 \%$ ( $4.1 \%$ men vs $3.6 \%$ women). The pre-existing T2DM was reported by three participants (10.7\%) while the proportion of newly diagnosed T2DM among T2DM cases was $89.3 \%$ (Table 2).

Mean values of the fasting blood glucose (FBG) within age groups, hypertension, body mass index (BMI), waist circumference (WC) and waist-to-hip ratio (WHR) are shown in Table 3. Considering the categories within the variables, the concentration of FBG significantly increased with advancing age and BMI. The highest blood 
Table 1 Description of the study participants

\begin{tabular}{|c|c|c|c|c|}
\hline Characteristics & Total & Men & Women & $\boldsymbol{p}$-value \\
\hline \multicolumn{5}{|l|}{ Biomedical $^{\mathrm{a}}$} \\
\hline Sample size, n (\%) & $385(100.0)$ & $197(51.2)$ & $188(48.8)$ & \\
\hline Age (years), mean (SD) & $37.77(15.66)$ & $36.47(15.63)$ & $39(15.61)$ & 0.094 \\
\hline BMI $\left(\mathrm{kg} / \mathrm{m}^{2}\right)$, mean (SD) & $25.67(5.97)$ & $23.17(4.11)$ & $28.28(6.49)$ & $<0.0001^{* *}$ \\
\hline Hip circumference (cm), mean (SD) & 100.09 (13.83) & $95.02(1.96)$ & $105.40(13.68)$ & $<0.0001^{* *}$ \\
\hline Weight (cm), mean (SD) & $70.87(15.16)$ & $63.31(12.74)$ & $73.56(16.97)$ & $0.001^{* *}$ \\
\hline \multicolumn{5}{|l|}{ Blood Glucose (mmol/L), mean (SD) } \\
\hline Fasting Blood Glucose & $5.385(1.211)$ & $5.286(0.888)$ & $5.478(1.449)$ & 0.141 \\
\hline Random Blood Glucose & $7.368(1.830)$ & $7.117(1.632)$ & $8.055(2.235)$ & 0.149 \\
\hline \multicolumn{5}{|l|}{$\mathrm{BP}(\mathrm{mm} \mathrm{Hg})$, mean $(\mathrm{SD})$} \\
\hline SBP & $123.13(16.22)$ & $122.64(13.99)$ & $123.64(18.29)$ & 0.549 \\
\hline DBP & $77.83(11.33)$ & $77.90(10.57)$ & $77.77(12.11)$ & 0.909 \\
\hline BMI $\left(\mathrm{kg} / \mathrm{m}^{2}\right), \mathrm{n}(\%)$ & & & & $<0.0001^{*}$ \\
\hline Underweight & $21(5.5)$ & $19(9.6)$ & $2(1.1)$ & \\
\hline Normal & $186(48.3)$ & $126(64.0)$ & $60(31.9)$ & \\
\hline Overweight & $102(26.5)$ & 39 (19.8) & $63(33.5)$ & \\
\hline Obese & $76(19.7)$ & $13(6.6)$ & $63(33.5)$ & \\
\hline Waist circumference (cm), n (\%) & & & & 0.855 \\
\hline Normal & $221(57.4)$ & $112(56.9)$ & $109(58.0)$ & \\
\hline Overweight & $59(15.3)$ & $29(14.7)$ & $30(16.0)$ & \\
\hline Obese & $105(27.3)$ & $56(28.4)$ & $49(26.1)$ & \\
\hline Waist-to-hip ratio, n (\%) & & & & 0.640 \\
\hline Normal & $247(64.2)$ & $129(65.5)$ & $118(62.8)$ & \\
\hline Overweight & $49(12.7)$ & $22(11.2)$ & $27(14.4)$ & \\
\hline Obese & $43(23.1)$ & $46(23.4)$ & $43(22.9)$ & \\
\hline Hypertension (mmHg), n (\%) & & & & 0.198 \\
\hline Normal & $142(36.9)$ & $68(34.5)$ & $74(39.4)$ & \\
\hline Elevated & $57(14.8)$ & $33(16.8)$ & $24(12.8)$ & \\
\hline Hypertension stage 1 & $113(29.4)$ & $63(32.0)$ & $50(26.6)$ & \\
\hline Hypertension stage 2 & $67(17.4)$ & $32(16.2)$ & 35 (18.6) & \\
\hline Hypertension crisis & $6(1.6)$ & $1(0.5)$ & $5(2.7)$ & \\
\hline \multicolumn{5}{|l|}{ Socioeconomic $^{b}$} \\
\hline Education, n (\%) & & & & 0.054 \\
\hline No formal education & $26(6.8)$ & $11(5.6)$ & $15(8.0)$ & \\
\hline Primary & $96(24.9)$ & $45(22.8)$ & $51(27.1)$ & \\
\hline Secondary & $101(26.2)$ & $44(22.3)$ & $57(30.3)$ & \\
\hline High school & $118(30.6)$ & $67(34.0)$ & $51(27.1)$ & \\
\hline College/university degree & $42(10.9)$ & $29(14.7)$ & $13(6.9)$ & \\
\hline Postgraduate degree & $2(0.5)$ & $1(0.5)$ & $1(0.5)$ & \\
\hline Occupation, n (\%) & & & & $0.022^{*}$ \\
\hline Student & $49(12.7)$ & $28(14.2)$ & $21(11.2)$ & \\
\hline Unemployed & $104(27.0)$ & $43(21.8)$ & $61(32.4)$ & \\
\hline Civil servant & $157(40.8)$ & $91(46.2)$ & $66(35.1)$ & \\
\hline Self employed & $58(15.1)$ & $30(15.2)$ & $28(14.9)$ & \\
\hline
\end{tabular}


Table 1 Description of the study participants (Continued)

\begin{tabular}{|c|c|c|c|c|}
\hline Characteristics & Total & Men & Women & $\boldsymbol{p}$-value \\
\hline Domestic worker & $8(2.1)$ & $1(0.5)$ & $7(3.7)$ & \\
\hline Shop attendant & $9(2.3)$ & $4(2.1)$ & $5(2.7)$ & \\
\hline Residence, n (\%) & & & & 0.331 \\
\hline Rural & $192(50.1)$ & $94(47.7)$ & $98(57.2)$ & \\
\hline Urban & $191(49.9)$ & $103(52.3)$ & $88(47.3)$ & \\
\hline Marital status, n (\%) & & & & 0.081 \\
\hline Single & $172(44.8)$ & $99(50.3)$ & $73(39.0)$ & \\
\hline Married & $157(40.9)$ & $74(37.6)$ & $83(44.4)$ & \\
\hline Staying with partner & $35(9.1)$ & $18(9.1)$ & $17(9.1)$ & \\
\hline Widowed & $14(3.6)$ & $5(2.5)$ & $9(4.8)$ & \\
\hline Divorced & $6(1.6)$ & $1(0.5)$ & $5(2.7)$ & \\
\hline Average monthly income (SDE), n (\%) & & & & $0.001^{*}$ \\
\hline$<500$ & $41(10.6)$ & $18(9.1)$ & $23(12.2)$ & \\
\hline $500-999$ & $66(17.1)$ & $23(11.7)$ & $43(22.9)$ & \\
\hline 1000-1999 & $92(23.9)$ & $41(20.8)$ & $51(27.1)$ & \\
\hline 2000-2999 & 74 (19.2) & $42(21.3)$ & $32(17.0)$ & \\
\hline$\geq 3000$ & $112(29.1)$ & 73 (37.1) & 39 (20.7) & \\
\hline
\end{tabular}

${ }^{\mathrm{ab}}$ Mean with SD for biomedical data and percentages for socio-demographic data

*Chi-square or Fisher's test, $p<0.05$ was considered significant for men vs women

**Univariate ANOVA, $p<0.05$ was considered significant for gender differences between men and women

BMI, Body mass index; BP, Blood pressure; DBP, Diastolic blood pressure; SBP, Systolic blood pressure; SD, Standard deviation; SDE: Swazi Emalangeni; $\mathrm{n}$,

Sample size

glucose concentration among women was observed within the age group of 55-64 years and within 45-54 years of age among men. Meanwhile, overweight and obese women (by BMI) had significantly higher blood glucose concentration levels than their counterparts of overweight and obese men $(p<0.0001)$. The blood glucose concentration levels were higher among hypertensive women than hypertensive men. Similar outcomes were obtained for gender distribution of those overweight and obese (by WC). However, the blood glucose concentration level was higher for obese men than that of obese women (by WHR).
Factors associated with pre-diabetes and type 2 diabetes mellitus

Factors associated with pre-diabetes

Table 4 shows the findings of chi-square analysis to identify the association between socioeconomic and demographic variables and the presence of diabetes and pre-diabetes (AGM). Individuals' age, raised blood pressure, and excess body weight were found to be significantly associated with pre-diabetes. Over half of the subjects with pre-diabetes were in the age group 45 years and older. The majority of the subjects with abnormal glucose were hypertensive, overweight or obese.

Table 2 Distribution of abnormal glucose metabolism according to age and gender

\begin{tabular}{|c|c|c|c|c|c|c|c|c|c|c|c|c|c|c|c|}
\hline \multirow[b]{3}{*}{ Age group (years) } & \multirow{2}{*}{\multicolumn{3}{|c|}{ Total }} & \multicolumn{6}{|c|}{ Crude Prevalence } & \multicolumn{6}{|c|}{ Age-adjusted Prevalence* } \\
\hline & & & & \multicolumn{3}{|c|}{ Proportion of pre-diabetes } & \multicolumn{3}{|c|}{ Proportion of T2DM } & \multicolumn{3}{|c|}{ Proportion of pre-diabetes } & \multicolumn{3}{|c|}{ Proportion of T2DM } \\
\hline & All & M & W & All & M & W & All & M & W & All & M & W & All & M & W \\
\hline $15-24$ & 91 & 49 & 42 & 1.0 & 0.5 & 0.5 & 1.0 & 0.0 & 1.0 & 1.0 & 0.9 & 1.0 & 1.0 & 0.0 & 2.0 \\
\hline $25-34$ & 108 & 63 & 45 & 1.3 & 1.3 & 0.0 & 1.3 & 0.5 & 0.8 & 0.6 & 0.9 & 0.0 & 0.6 & 0.4 & 0.8 \\
\hline $35-44$ & 84 & 40 & 44 & 0.3 & 0.0 & 0.2 & 1.8 & 0.5 & 1.3 & 0.1 & 0.0 & 0.2 & 0.7 & 0.4 & 1.0 \\
\hline $45-54$ & 40 & 13 & 27 & 1.6 & 1.0 & 0.5 & 1.3 & 0.0 & 1.3 & 0.9 & 1.6 & 0.5 & 0.8 & 0.0 & 1.3 \\
\hline $55-64$ & 31 & 17 & 14 & 1.8 & 0.8 & 1.0 & 0.8 & 0.3 & 0.5 & 1.0 & 0.7 & 1.3 & 0.4 & 0.2 & 0.7 \\
\hline $65+$ & 31 & 15 & 16 & 0.5 & 0.0 & 0.5 & 1.0 & 0.3 & 0.8 & 0.3 & 0.0 & 0.6 & 0.5 & 0.2 & 0.9 \\
\hline Total & 385 & 197 & 188 & 6.5 & 3.6 & 2.7 & 7.3 & 1.6 & 5.7 & 3.8 & 4.1 & 3.6 & 3.9 & 1.2 & 6.6 \\
\hline
\end{tabular}

M, men; W, women

*Based on the Swaziland Demographic and Health Survey 2006/07 [19] (See supplementary Table 1) 
Table 3 Mean glucose concentrations (mmol/L) according to gender

\begin{tabular}{|c|c|c|c|c|}
\hline Variables & Men & Women & Total & $\boldsymbol{P}$-value \\
\hline Sample, n (\%) & $167(48.5)$ & $177(51.5)$ & $344(100.0)$ & \\
\hline Age groups (years), mean (SD) & & & & $<0.0001^{* *}$ \\
\hline $15-24$ & $4.989(0.7534)^{*}$ & $5.154(1.1734)^{*}$ & $5.066(0.9708)$ & \\
\hline $25-34$ & $5.275(0.6706)$ & $5.152(0.8303)$ & $5.222(0.7424)$ & \\
\hline $35-44$ & $5.260(0.6162)$ & $5.395(1.3199)$ & $5.337(1.0118)$ & \\
\hline $45-54$ & $5.500(0.8234)$ & $5.958(2.0777)$ & $5.813(1.7790)$ & \\
\hline $55-64$ & $5.693(0.7918)$ & $5.879(1.2540)$ & $5.786(1.0334)$ & \\
\hline $65+$ & $5.800(2.0356)$ & $6.200(2.1147)$ & $6.029(2.0526)$ & \\
\hline Hypertension, mean (SD) & & & & 0.175 \\
\hline Normal & $5.277(1.1124)$ & $5.277(1.4334)$ & $5.277(1.2903)$ & \\
\hline Elevated (Prehypertension) & $5.281(0.7547)$ & $5.187(0.7724)$ & $5.241(0.7565)$ & \\
\hline Hypertension stage 1 & $5.114(0.6338)$ & $5.778(1.5632)$ & $5.436(1.2191)$ & \\
\hline Hypertension stage 2 & $5.622(0.8078)$ & $5.661(1.5967)$ & 5.645 (1.3189) & \\
\hline Body mass index, mean (SD) & & & & $<0.0001^{* *}$ \\
\hline Underweight & $5.073(0.7005)^{*}$ & $4.450(0.2121)$ & $5.012(0.6800)$ & \\
\hline Normal & $5.164(0.7260)$ & $5.297(1.4047)$ & $5.211(1.0182)$ & \\
\hline Overweight & $5.691(1.2969)$ & $5.809(0.8469)$ & 5.765 (1.6582) & \\
\hline Obese & $5.454(0.6741)$ & $5.363(0.9437)$ & 5.379 (0.8976) & \\
\hline Waist circumference, mean (SD) & & & & 0.706 \\
\hline Normal & $5.237(0.7175)$ & $5.426(1.1279)$ & 5.337 (0.9589) & \\
\hline Overweight & $5.254(1.6173)$ & $5.557(1.6577)$ & $5.422(1.6315)$ & \\
\hline Obese & $5.385(0.6804)$ & $5.542(1.9101)$ & $5.458(1.3872)$ & \\
\hline Waist-to-hip ratio, mean (SD) & & & & 0.850 \\
\hline Normal & $5.219(0.7566)$ & $5.493(1.1921)$ & $5.358(1.0084)$ & \\
\hline Overweight & $5.319(1.6500)$ & $5.563(1.7425)$ & $5.456(1.6891)$ & \\
\hline Obese & $5.451(0.6099)$ & $5.380(1.8600)$ & $5.415(1.3829)$ & \\
\hline
\end{tabular}

Hypertension is defined as normal (SBP $<120$ and DBP $<80 \mathrm{mmHg}$ ), Elevated (SBP 120-129 and DBP $<80$ mmHg); hypertension stage 1 (SBP $130-139$ or DBP $80-$ $89 \mathrm{mmHg})$; hypertension stage $2(\mathrm{SBP} \geq 140$ or $\mathrm{DBP} \geq 90 \mathrm{mmHg})$

BMI defined as underweight $(<18.5)$, normal (18.5-24.9), overweight (25.0-29.9) and obese $(\geq 30)$

Waist circumference is defined as normal, overweight and obese for men $(<94,94-102$ and $\geq 103 \mathrm{~cm})$ and women $(\leq 80,80-88$, and $\geq 89 \mathrm{~cm})$, respectively Waist-to-hip ratio is defined as normal, overweight and obese for men $(\leq 0.95,0.96-1.0$ and $\geq 1.1)$ and women $(\leq 0.80,0.81-0.85$, and $\geq 0.86)$, respectively $\mathrm{n}$, number; ${ }^{*} p<0.05$ and ${ }^{* *} p<0.05$ significant by Univariate ANOVA (F-test) for gender difference in subgroup and group, respectively

\section{Factors associated with T2DM}

Gender and wealth index were the non-modifiable and modifiable risk factors found to be associated with T2DM. A significant proportion of women compared to men were found to have T2DM (78.6\% vs $21.4 \%)$. Moreover, subjects with T2DM were found to be significantly poorer than subjects with normal glucose metabolism (39.3\% vs $17.5 \%$ ). Body mass index, education, occupation and household income were also found to be associated with T2DM, but these did not reach the level of statistical significance $(p>0.05)$.

\section{Discussion}

In this study the researchers reported estimates for the prevalence of T2DM and pre-diabetes, and the factors associated with these conditions among adults (18-83 years old) attending outpatient departments at the RFM in Swaziland. The overall prevalence of T2DM and prediabetes was 7.3 and $6.5 \%$, respectively, with clear gender differences. The results showed a higher prevalence of T2DM (7.3\%) than previously reported (5\%) in this hospital. Similarly, the proportion of newly detected T2DM cases $(89.3 \%)$ was high, suggesting that screening practices in this hospital were ineffective. Advancing age, female gender, excess body weight, poorest wealth index and high blood pressure were associated with a higher risk of T2DM and pre-diabetes in these Swazi adults.

The estimated T2DM prevalence of $7.3 \%$ found in the current study was higher than the $5.0 \%$ reported previously by Rabkin et al. [10] in the same setting, but lower than the estimate reported in the 2014 STEPS survey [3] in Swaziland. The difference between Rabkin et al.'s 
Table 4 Demographic and socio-economic factors associated with diabetes status

\begin{tabular}{|c|c|c|c|c|c|}
\hline \multirow[t]{2}{*}{ Variable } & \multirow[t]{2}{*}{$N_{G M}{ }^{\mathbf{b}}$} & \multicolumn{4}{|l|}{$A G M^{a}$} \\
\hline & & Prediabetes & $\boldsymbol{p}$-value & T2DM & $\boldsymbol{p}$-value \\
\hline Sample, n (\%) & $332(86.2)$ & $25(6.5)$ & & $28(7.3)^{c}$ & \\
\hline Mean age (SD) & $36.58(15.01)$ & $45.68(17.35)$ & & $44.82(18.5)$ & \\
\hline Age (years) (n, \%) & & & $0.001^{*}$ & & 0.255 \\
\hline $15-24$ & $83(25.0)$ & $4(6.0)$ & & $4(14.3)$ & \\
\hline $25-34$ & $98(29.5)$ & $5(20.0)$ & & $5(17.9)$ & \\
\hline $35-44$ & $76(22.9)$ & $1(4.0)$ & & $7(25.0)$ & \\
\hline $45-54$ & $29(8.7)$ & $6(24.0)$ & & $5(17.9)$ & \\
\hline $55-64$ & $21(6.3)$ & $7(28.0)$ & & $3(10.7)$ & \\
\hline $65+$ & $25(7.5)$ & $2(8.0)$ & & $4(14.3)$ & \\
\hline Gender (n, \%) & & & 0.795 & & $0.001^{*}$ \\
\hline Men & $177(53.3)$ & $14(56.0)$ & & $6(21.4)$ & \\
\hline Women & $155(46.7)$ & $11(44.0)$ & & $22(78.6)$ & \\
\hline Residence $(\mathrm{n}, \%)$ & & & 0.563 & & 0.717 \\
\hline Rural & $165(50.0)$ & $14(56.0)$ & & $13(46.4)$ & \\
\hline Urban & $165(50.0)$ & $11(44.0)$ & & $15(53.6)$ & \\
\hline Marital status (n, \%) & & & 0.131 & & 0.371 \\
\hline Not in union ${ }^{d}$ & $171(51.7)$ & $9(36.0)$ & & $12(42.9)$ & \\
\hline In union ${ }^{e}$ & $160(48.3)$ & $16(64.0)$ & & $16(57.1)$ & \\
\hline Hypertension (n, \%) & & & $0.046^{*}$ & & 0.710 \\
\hline Normal & $127(38.3)$ & $4(16.0)$ & & $11(38.3)$ & \\
\hline Elevated & $51(15.4)$ & $3(12.0)$ & & $3(10.7)$ & \\
\hline Stage 1 & $97(29.2)$ & $9(36.0)$ & & $7(25.0)$ & \\
\hline Stage 2 & $57(17.2)$ & $9(36.0)$ & & $7(25.0)$ & \\
\hline Body mass index (n, \%) & & & $0.042^{*}$ & & 0.052 \\
\hline Underweight & $20(6.0)$ & $1(4.0)$ & & $0(0.0)$ & \\
\hline Normal & $170(51.2)$ & $6(24.0)$ & & $10(35.7)$ & \\
\hline Overweight & $80(24.1)$ & $10(40.0)$ & & $12(42.9)$ & \\
\hline Obese & $62(18.7)$ & $8(32.0)$ & & $6(21.4)$ & \\
\hline Waist circumference $(n, \%)$ & & & 0.155 & & 0.543 \\
\hline Normal & $189(56.9)$ & $19(76.0)$ & & $13(46.4)$ & \\
\hline Overweight & $52(15.7)$ & $2(8.0)$ & & $5(17.9)$ & \\
\hline Obese & $91(27.4)$ & $4(16.0)$ & & $10(35.7)$ & \\
\hline Waist-to-hip ratio (n, \%) & & & $0.025^{*}$ & & 0.221 \\
\hline Normal & $210(63.3)$ & $22(88.0)$ & & $15(53.6)$ & \\
\hline Overweight & $41(12.3)$ & $1(4.0)$ & & $7(25.0)$ & \\
\hline Obese & $81(24.4)$ & $2(8.0)$ & & $6(21.4)$ & \\
\hline Education (n, \%) & & & 0.154 & & 0.087 \\
\hline No formal education & $19(5.7)$ & $4(16.0)$ & & $3(10.7)$ & \\
\hline Primary & $78(23.5)$ & $7(28.0)$ & & $11(39.3)$ & \\
\hline Secondary or higher & $235(70.8)$ & $14(56.0)$ & & $14(50.0)$ & \\
\hline Occupation (n, \%) & & & 0.596 & & 0.069 \\
\hline Student/unemployed & $129(38.9)$ & $10(40.0)$ & & $14(50.0)$ & \\
\hline Self-employed & 49 (14.8) & $2(8.0)$ & & $7(25.0)$ & \\
\hline
\end{tabular}


Table 4 Demographic and socio-economic factors associated with diabetes status (Continued)

\begin{tabular}{|c|c|c|c|c|c|}
\hline \multirow[t]{2}{*}{ Variable } & \multirow[t]{2}{*}{$N_{G M}{ }^{\mathbf{b}}$} & \multicolumn{4}{|l|}{$A G M^{a}$} \\
\hline & & Prediabetes & $\boldsymbol{p}$-value & T2DM & $\boldsymbol{p}$-value \\
\hline Salaried job & $154(46.4)$ & $13(52.0)$ & & $7(25.0)$ & \\
\hline Household income (SDE) ( $n, \%)$ & & & 0.977 & & 0.065 \\
\hline$<999$ & $87(26.2)$ & $7(28.0)$ & & $13(46.4)$ & \\
\hline 1000-2999 & $147(44.3)$ & $11(44.0)$ & & $8(28.6)$ & \\
\hline$\geq 3000$ & $98(29.5)$ & $7(28.0)$ & & $7(25.0)$ & \\
\hline Wealth index $(n, \%)$ & & & 0.480 & & $0.003^{*}$ \\
\hline Poorest & $58(17.5)$ & $6(24.0)$ & & $11(39.3)$ & \\
\hline Second & $72(21.7)$ & $2(8.0)$ & & $5(17.9)$ & \\
\hline Middle & $64(19.3)$ & $6(24.0)$ & & $0(0.0)$ & \\
\hline Fourth & $64(19.3)$ & $5(20.0)$ & & $5(17.9)$ & \\
\hline Richest & $74(22.3)$ & $6(24.0)$ & & $7(25.0)$ & \\
\hline
\end{tabular}

${ }^{\mathrm{a}} \mathrm{AGM}$, abnormal glucose metabolism; ${ }^{\mathrm{b}} \mathrm{NGM}$, normal glucose metabolism; ${ }^{\mathrm{c}}$ contains $3(10.7 \%)$ previously diagnosed cases; ${ }^{\mathrm{d}}$ includes single, widow, staying with partner;

eincludes married, staying with partner; $\mathrm{n}$, number; ${ }^{*}$ chi-square statistic significant at $p<0.05$

estimate and the current study could be due to differences in the diagnostic criteria used. As pointed out by the authors, glycated hemoglobin may have underestimated the prevalence of T2DM since the subjects were HIV-infected. Similarly, the possible differences in the STEPS survey's estimate and the current study may have been due to the use of higher cut-off points in the current study. In the STEPS survey, T2DM was defined as a blood glucose reading of $\geq 6.1 \mathrm{mmol} / \mathrm{L}$ compared to a blood glucose reading of $\geq 7.0 \mathrm{mmol} / \mathrm{L}$ used in the current study.

This study's reported prevalence rate for T2DM was much higher than those reported in many studies in the Southern African sub-continent [20-22], but lower than those found in some studies in South Africa by Werfalli et al. [23] and Oni et al. [24]. The difference between the T2DM prevalence rate in the current study and estimate by Werfalli et al. could have been due differences in participants' age groups (older adults $\geq 50$ years) and the use of self-report diagnosis instead of screening and diagnosis. It is known that the prevalence of T2DM peaks at around age 50 years [25], therefore, a higher prevalence estimate in Werfalli et al.'s study was expected. Similarly, the study by Oni et al. [24] used different diagnostic criteria (glycated haemoglobin (HbAlc)) compared to the current study which used fasting blood glucose (FBG). Oni et al. reported a lower prevalence rate for T2DM (4.1\%) when diagnosed with FBG [24].

The high prevalence of newly diagnosed T2DM (89.3\%) among patients found to have T2DM in the current study was consistent with the previous report in Swaziland [3] and evidence from South Africa [26], but higher than those (25-56.8\%) reported in SSA [20, 21, $24,27]$. The implication of the high rate of newly diagnosed T2DM among T2DM cases was that without this study, these diabetic cases may not have sought health care for their condition until complications had set in. Moreover, the higher prevalence of newly detected cases of T2DM suggested that current screening practices in this hospital and SSA were ineffective [28]. Therefore, screening of high-risk individuals should be incorporated in the clinical practice at outpatient departments in this hospital.

The prevalence of pre-diabetes estimated in the current study (6.5\%) was higher than the rates reported elsewhere in SSA: Kenya [29]; Malawi [30]; Uganda [31]; and South Africa [32]. Pre-diabetes is an intermediate metabolic state between normal glucose metabolism and T2DM, which are higher than normal glucose level and could progress to T2DM [13]. An IDF publication [33] estimated the prevalence of IGT to vary between 2.2 and $16 \%$ in Africa and asserted that the burden of T2DM would continue to escalate if nothing was done to curb the epidemy of IGT. It is therefore vital that these-atrisk groups be targeted for lifestyle changes to prevent full-blown T2DM in these individuals.

As expected, pre-diabetes was significantly associated with advancing age, consistent with previous reports in SSA [34-36]. However, a study in rural Uganda did not find an association between BMI and AGM [37], probably due to the younger age groups included ( $\geq 13$ years) in their sample and the use of random blood glucose instead of fasting blood glucose results. In the current study, the proportion of obese women was significantly higher than the proportion of obese men. A possible explanation for this finding is that women are known to have higher rates of abdominal fat and insulin resistance than men [38]. These biological risk factors are 
associated with a higher risk of T2DM [38]. Furthermore, hypertension was significantly associated with prediabetes in the current study in agreement with report elsewhere in SSA [35]. A study in Nigeria by Okpechi et al. [39] showed a high prevalence of hypertension in SSA. Many complex factors have been identified as possible reasons for this, including high salt intake, low physical activity, and genetic vulnerability to high blood pressure [39]. Therefore, these high-risk groups should be targeted for lifestyle education, particularly the need for self-monitoring of body weight and periodic checks on fasting blood glucose. The outpatient departments in this setting need to include these clinical checks and lifestyle education in their routine services.

Type 2 diabetes mellitus was associated with advancing age, consistent with previous reports in SSA [34-36]. Surprisingly, this association did not reach the level of statistical significance, probably due to the small number of T2DM cases. Also, the highest glucose concentration was found in subjects over the age of 45 years (45-64 years) comparable to findings from previous reports from South Africa [40] and Cameroon [41]. The significant gender differences observed in the prevalence rates for T2DM in the current study were consistent with findings in subSaharan Africa [42-44]. The wealth index was associated with elevated glucose levels in the current study, consistent with previous reports from Malawi [20] and elsewhere in Europe [45]. Most of the subjects with T2DM (39.3\%) were significantly poorer compared with subjects with normal glucose metabolism (17.5\%). The inequality observed in the gender distribution of the socio-economic variables in the current study was concerning. A significant proportion of diabetic women compared to diabetic men were poorly educated, unemployed and poor. This may possibly have been due to the gender division of labour in Swaziland. A greater proportion of women in Swaziland were vulnerable and excluded from strategic gender roles [19]. Therefore, measures to improve the socio-economic status of women are warranted in Swaziland to curb the growing diabetes in the kingdom.

\section{Strengths and limitations of the study}

The major strength of this study was the fact that the diagnosis of T2DM was based on the analysis of the blood samples. This prevented recall bias associated with a self-reported diabetes status. To researchers' knowledge, this study provided the first age-adjusted estimates of the prevalence of diabetes and pre-diabetes in Swaziland. These data provided a baseline upon which cost-effective and culturally acceptable intervention could be devised to address the growing burden of diabetes in Swaziland.
The major limitation of the present study was that the prevalence rates for abnormal glucose metabolism (prediabetes and T2DM) were determined based on the assumption that the participants who presented themselves had fasted for $8 \mathrm{~h}$ before screening and diagnosis. The use of glycated hemoglobin (HbA1c) would have improved the reliability of the data since the need for fasting would have been eliminated. Furthermore, the patients who presented themselves at the OPD in the hospital may not have been representative of the larger Swazi population. Therefore, extrapolating these findings to the general Swazi population should be done with caution. Lastly, some of the known risk factors of diabetes (such as genetic predisposition) were not investigated in this study.

The study's findings highlighted the need for the Swazi government to adopt policies to reduce the burden of T2DM in the Kingdom through healthcare services, with a special focus on women. This is important if the kingdom hopes to achieve the ambitious Sustainable Development [46] Goal number three (target 3.4) of reducing the NCD pre-mature mortality by one-third by 2030 .

\section{Conclusions}

In conclusion, this study reported a higher prevalence of both T2DM, and pre-diabetes than previously reported among patients in this hospital. This study also found an increasing prevalence of T2DM and pre-diabetes with advancing age. Unfortunately, most patients with T2DM in this study were newly diagnosed for the disease. This indicated that the screening practices in this hospital were not effective. Therefore, it is suggested that a routine blood glucose test be incorporated into healthcare services at outpatient departments in this hospital. As demonstrated in previous studies in Swaziland and elsewhere, the findings affirmed the hypothesis that modifiable risk factors play important role in the rising prevalence of T2DM in developing countries. Hence, cost-effective and culturally acceptable health education measures are needed to promote a healthy lifestyle among patients in this setting to halt the rising burden of T2DM in Swaziland.

\section{Supplementary information}

Supplementary information accompanies this paper at https://doi.org/10. 1186/s12889-020-08489-9.

Additional file 1: Supplementary file 1. Crude and age-adjusted prevalence rates of pre-diabetes and type 2 diabetes mellitus.

\section{Abbreviations}

AGM: Abnormal Glucose Metabolism; IFG: Impaired Fasting Glucose; IGT: Impaired Glucose Tolerance; SSA: Sub-Saharan Africa; T2DM: Type 2 Diabetes Mellitus 


\section{Acknowledgements}

Not applicable.

\section{Authors' contributions}

MG reviewed the literature, made substantial contributions to the conception, design, and drafting of the manuscript. BT participated in the design of the study and/or the drafting of the manuscript. Both authors read and approved the final manuscript.

\section{Funding}

This work was supported by The College of Health Sciences Scholarship for PhD students. The funding body did not play any role in the design of the study and writing of the manuscript. The study protocol has not undergone peer-review by the funding body.

\section{Availability of data and materials}

All data generated or analysed during this study are included in this published article [and its supplementary information files].

\section{Ethics approval and consent to participate}

Ethical approval was obtained from the Biomedical Research Ethics Committee (BREC) of the University of KwaZulu-Natal, Durban, South Africa (BE 385/18) and the Research Ethics Committee of the Swaziland Ministry of Health. Relevant permission was obtained from the hospital administration, while all participants gave informed written consent to participate in the study. Confidentiality was maintained in accordance with standard medical practice.

\section{Consent for publication}

Not applicable.

\section{Competing interests}

The authors declare that they have no competing interests.

Received: 28 August 2019 Accepted: 9 March 2020

Published online: 26 March 2020

\section{References}

1. International Diabetes Federation. IDF Diabetes Atlas. Brussels: International Diabetes Federation; 2017

2. World Health Organisation. Diabetes Country Profile: Swaziland 2016. www. who.int/nmh/countries/swz_en.pdf?ua=1. Accessed 23 May 2017.

3. Ministry of Health. 2014 WHO STEPS non-communicable disease risk factor surveillance report. Mbabane: Ministry of Health; 2015.

4. Ministry of Health. Annual Non-Communicable Diseases Program Report Mbabane: Ministry of Health; 2017.

5. Ministry of Health, Swaziland. National Non-Communicable Diseases Policy. Mbabane: Ministry of Health; 2016.

6. Ministry of Health, Swaziland. National Non-Communicable Diseases Prevention and Control Strategy 2012-2017. Mbabane: Ministry of Health; 2012.

7. Mngomezulu N, Yang CC. Quality of life and its correlates in diabetic outpatients in Swaziland. Int Health. 2015;7(6):464-71.

8. Burn H, Pon J. Diabetic retinopathy in Swaziland. Comm Eye Health. 2015; 28(92):S18-21.

9. Rabkin M, Palma A, McNairy ML, Gchuhi AB, Simelane S, NuwagabaBiribonwoha $\mathrm{H}$, et al. Strengthening health Systems for Chronic Care: leveraging HIV programs to support diabetes Services in Ethiopia and Swaziland. J Trop Med. 2012;2012:137460.

10. Rabkin M, Melaku Z, Bruce K, Reja A, Koler A, Tadesse Y, et al. Integrating cardiovascular disease risk factor screening into HIV services in Swaziland: lessons from an implementation science study. AIDS. 2018;32(Suppl):S43-6.

11. Castillo JJ. Systematic sampling. http://www.scribd.com/doc/54018519/ Systematic-sampling. Accessed 23 Mar 2016.

12. Daniel WW. Biostatistics: A Foundation for Analysis in the Health Sciences. 7th ed. New York: Willey; 1999.

13. World Health Organization. Screening for type 2 diabetes: report of the World Health Organization and the international diabetes federation. Geneva: World Health Organization; 2003.

14. Vyas S, Kumaranayake L. Constructing socio-economic status indices: how to use principal components analysis. London: Oxford University Press; 2006.
15. World Health Organization. Obesity: preventing and managing the global epidemic. Geneva: World Health Organization; 2000.

16. World Health Organization. Waist circumference and waist-hip ratio: report of a WHO expert consultation. Geneva: World Health Organisation; 2011.

17. Whelton PK, Carey RM, Aronow WS, et al. 2017 ACC/AHA/AAPA/ABC/ACPM/ AGS/APhA/ASH/ASPC/NMA/PCNA Guideline for the Prevention, Detection, Evaluation, and Management of High Blood Pressure in Adults: a report of the American College of Cardiology/American Heart Association Task Force on Clinical Practice Guidelines. Hypertension. 2018;71(6):e13-e115. https:// doi.org/10.1161/HYP.0000000000000065.

18. Miller BJ. Type 2 diabetes mellitus in the Arumeru district of northern Tanzania: evaluation of the prevalence and associated risk factors in rural communities. [dissertation]. Washington: Washington State University; 2013.

19. Central Statistical Office (CSO) [Swaziland] Macro International Inc. Swaziland Demographic and Health Survey 2006-07. Mbabane: Central Statistical Office and Macro International Inc.; 2008.

20. Price AJ, Crampin AC, Amberbir A, Kayuni-Chihana N, et al. Prevalence of obesity, hypertension, and diabetes, and cascade of care in sub-Saharan Africa: a cross-sectional, population-based study in rural and urban Malawi. Lancet Diabetes Endocrinol. 2018;6:208-22.

21. Bailey SL, Ayles H, Beyers N, Godfrey-Faussett P, Muyoyeta M, du Toit E, et al. Diabetes mellitus in Zambia and the Western cape province of South Africa: prevalence, risk factors, diagnosis and management. Diabetes Res Clin Practice. 2016;118:1-11.

22. Silva-Matos C, Gomes A, Azevedo A, Damasceno A, Prista A, Lunet N. Diabetes in Mozambique: prevalence, management and healthcare challenges. Diabetes Metab. 2011;37(3):237-44.

23. Werfalli M, Kassanjeeb R, Kalulac S, Kowal P, Phaswana-Mafuyaf N, Levitt NS. Diabetes in south African older adults: prevalence and impact on quality of life and functional disability - as assessed using SAGE wave 1 data. Glob Health Action. 2018;11:1449924.

24. Oni T, Berkowitz N, Kubjane M, Goliath R, Levitt NS, Wilkinson RJ. Trilateral overlap of tuberculosis, diabetes and HIV-1 in a high-burden African setting: implications for TB control. Eur Respir J. 2017:50:1700004.

25. Erasmus RT, Soita DJ, Hassan MS, Blanco-Blanco E, Vergotine Z, Kengne AP, et al. High prevalence of diabetes mellitus and metabolic syndrome in a south African coloured population: baseline data of a study in Bellville, Cape Town. South Afr Med J. 2012;102(11):841-4.

26. Motala AA, Esterhuizen T, Gouws E, Pirie FJ, Omar MA. Diabetes and other disorders of glycemia in a rural south African community: prevalence and associated risk factors. Diabetes Care. 2008;31(9):1783-8.

27. Christensen DL, Friis H, Mwaniki D, Kilonzo B, Tetens I, Boit M, et al. Prevalence of glucose intolerance and associated risk factors in rural and urban populations of different ethnic groups in Kenya. Diabetes Res Clin Practice. 2009:84(3):303-10.

28. Hall V, Thomsen RW, Henriksen O, Lohse N. Diabetes in Sub Saharan Africa 1999-2011: epidemiology and public health implications. A systematic review. BMC Public Health. 2011;11(1):564.

29. Mohamed SF, Mwangi M, Mutua MK, Kibachio J, Hussein ZN, et al. Prevalence and factors associated with prediabetes and diabetes mellitus in Kenya: results from a national survey. BMC Public Health. 2018;18(Suppl 3): 1215 https://doi.org/10.1186/s12889-018-6053-x.

30. Msyamboza KP, Mvula CJ, Kathyola D. Prevalence and correlates of diabetes mellitus in Malawi: population-based national NCD STEPS survey. BMC Endocr Disord. 2014;14(1):41.

31. Bahendeka S, Wesonga R, Mutungi G, Muwinge J, Neema S, Gwatude D. Prevalence and correlates of diabetes mellitus in Uganda: a populationbased national survey. Tropical Med Int Health. 2016;21(3):405-16.

32. Stokes A, Berry KM, Mchiza Z, Parker W, Labadarios D, Chola L, et al. Prevalence and unmet need for diabetes care across the care continuum in a national sample of south African adults: evidence from the SANHANES-1, 2011-2012. PLoS One. 2017;12(10):e0184264.

33. Sicree R, Shaw J, Zimmet P. Global Burden Diabetes Prediabetes IDF Diabetes Atlas 2012; 4: 15.

34. Abebe SM, Berhane Y, Worku A, Assefa A. Diabetes mellitus in north West Ethiopia: a community-based study. BMC Public Health. 2014;14:97.

35. Baldé NM, Camara A, Diallo AA, Kake A, Diallo AM, Diakite M, Bah C, Kone $M$. Prevalence and awareness of diabetes in Guinea: findings from a WHO STEPS. J Endocrinol Metab Diabetes S Afr. 2017;22(3):36-42.

36. Mbanya JC, Cruickshank JK, Forrester T, Balkau B, Ngogang JY, Riste L, Forhan A, Anderson NM, Bennett F, Wilks R. Standardized comparison of 
glucose intolerance in west African-origin populations of rural and urban Cameroon, Jamaica, and Caribbean migrants to Britain. Diabetes Care. 1999; 22(3):434-40.

37. Maher D, Waswa L, Baisley K, Karabarinde A, Unwin N, et al. Distribution of hyperglycaemia and related cardiovascular disease risk factors in lowincome countries: a cross-sectional population-based survey in rural Uganda. Int J Epidemiol. 2011;40:160-71.

38. Wannamethee SG, Papacosta O, Lawlor DA, Whincup PH, Lowe GD, Ebrahim S, Sattar N. Do women exhibit greater differences in established and novel risk factors between diabetes and non-diabetes than men? The British regional heart study and British Women's heart health study. Diabetologia. 2012;55(1):80-7.

39. Okpechi IG, Chukwuonye II, Tiffin N, Madukwe OO, Onyeonoro UU, Umeizudike TI, Ogah OS. Blood pressure gradients and cardiovascular risk factors in urban and rural populations in Abia state south eastern Nigeria using the WHO STEPwise approach. PLoS One. 2013;8(9):e73403.

40. Peer N, Steyn K, Lombard C, Lambert EV, Vythilingum B, Levitt NS. Rising diabetes prevalence among urban-dwelling black South Africans. PloS One. 2012;7(9):e43336.

41. Sobngwi E, Mbanya JC, Unwin NC, Porcher R, Kengne AP, et al. Exposure over the life course to an urban environment and its relation with obesity, diabetes, and hypertension in rural and urban Cameroon. Int J Epidemiol. 2004;33:769-76.

42. Ekpenyong CE, Akpan UP, Ibu JO, Nyebuk DE. Gender and age specific prevalence and associated risk factors of type 2 diabetes mellitus in Uyo metropolis, south eastern Nigeria. Diabetol Croat. 2012:41(1):17-28.

43. Gatimu SM, Milimo BW, Sebastian MS. Prevalence and determinants of diabetes among older adults in Ghana. BMC Public Health. 2016;16:1174.

44. Groenewald AJ, van Wyk HJ, Walsh CM, van Zyl S, van der Merwe LJ. Prevalence of diabetes mellitus in the rural southern Free State. S Afr Fam Pract. 2009;51(6):502-5.

45. Espelt A, Borrell C, Palencia L, Goday A, Spadea T, Gnavi R, et al, Socioeconomic inequalities in the incidence and prevalence of type 2 diabetes mellitus in Europe. Gac Sanit. 2013;27:494-501.

46. United Nations. Transforming our world: the 2030 agenda for sustainable development (a/RES/70/1). New York: United Nations General Assembly; 2015.

\section{Publisher's Note}

Springer Nature remains neutral with regard to jurisdictional claims in published maps and institutional affiliations.

Ready to submit your research? Choose BMC and benefit from:

- fast, convenient online submission

- thorough peer review by experienced researchers in your field

- rapid publication on acceptance

- support for research data, including large and complex data types

- gold Open Access which fosters wider collaboration and increased citations

- maximum visibility for your research: over $100 \mathrm{M}$ website views per year

At $\mathrm{BMC}$, research is always in progress.

Learn more biomedcentral.com/submissions 